\title{
Colaboración público-privada y transferencia de riesgos ${ }^{*}$
}

\section{Public-private collaboration and risk transfer}

\author{
Julio González García ${ }^{(*)}$ \\ Universidad Complutense de Madrid (Madrid, España)
}

Resumen: El estudio analiza las consecuencias que tiene la aplicación del principio de estabilidad presupuestaria sobre el clausulado de los mecanismos de colaboración público-privada. En particular, cómo configurar un adecuado reparto de riesgos y especialmente cómo se estructuran los apoyos públicos puede determinar que compute como déficit público a los efectos de la doctrina de Eurostat sobre el SEC 95.

Palabras clave: Estabilidad presupuestaria - Colaboración público-privada - SEC 2010 - Eurostat

Abstract: The study analyses the implications of implementing the principle of budgetary stability on the clauseing of public-private partnership mechanisms. In particular, how to set up adequate risk-sharing and especially how public supports are structured can determine that compute as a public deficit for the purposes of Eurostat's SEC 95 doctrine.

Keywords: Budgetary Stability - Public-Private Partnership - SEC 2010 - Eurostat

$\left(^{*}\right) \quad$ Nota del Editor: Este artículo fue recibido el 29 de enero de 2021 y su publicación fue aprobada el 29 de marzo de 2021.

${ }^{* *}$ Doctor en Derecho por la Universidad Complutense de Madrid. Catedrático de Derecho Administrativo en la Universidad Complutense de Madrid y Director del Instituto de Derecho Europeo e Integración Regional. ORCID: https://orcid.org/0000-0003-4246-1326. Correo electrónico: juliogonzalezgarcia@me.com. 


\section{Consideraciones generales}

La construcción de infraestructuras públicas es fuente en este momento de una tensión importante entre la situación financiera de las Administraciones públicas y una reclamación constante por parte de la ciudadanía. No es un problema que derive sólo de la crisis económica que se inició en 2008 como consecuencia de las hipotecas subprime en los Estados Unidos de América, ni siquiera de la crisis provocada por la pandemia del COVID-19, sino que, aunque con mucha menor virulencia, se remonta a algunos años antes, concretamente a la aprobación del Pacto de Estabilidad y Crecimiento, adoptado por Resolución del Consejo Europeo celebrado en Amsterdam el 17 de junio de 1997. Este pacto fue un instrumento clave para el establecimiento del euro como moneda común, y exigió la adopción de determinadas medidas de contención austeridad económica pública, a fin de garantizar una solvencia suficiente de la economía europea, que pudiera permitir el establecimiento de una moneda única.

Esta conveniencia de que se adopten medidas de rigor presupuestario están recogidas en la actualidad en el artículo 126 del Tratado de Funcionamiento de la Unión Europea ${ }^{(1)}$, que dispone sucintamente que "Ios Estados miembros evitarán déficits públicos excesivos".

Dentro de las partidas que tienen más impacto en el déficit público, la construcción de infraestructuras es una de las primordiales. Los instrumentos de medición de la situación económica de los entes públicos europeos, desarrollados por Eurostat -Oficina Estadística de la Comisión Europea-(2), afectan muy relevantemente a la política de infraestructuras de los entes públicos, condicionando las que se pueden llevar a cabo, moralizando las formas de ejecución, de manera que se puede señalar que el auge y la desaparición de algunas modalidades deriva directamente de la aplicación de los criterios de Eurostat sobre el déficit público. Así, por ejemplo, el auge y caída del denominado modelo alemán de ejecución de obras -esto es, el contrato con abono total del precio- es consecuencia directa de la variación en los criterios contables sobre el déficit público del Estado que lo utilice.

La propia utilización de los modelos de colaboración público-privada es también consecuencia de cómo se trata contablemente a los efectos del déficit público la estructuración de los riesgos que están en el contrato, mediante la modificación de la prestación característica del contrato y, al mismo tiempo, una transferencia suficiente de los riesgos al socio privado. Usualmente, la modificación en la mayor parte de los casos de la prestación característica que deja de ser construcción de bienes, pasando a ser prestación de servicios es lo que permite fomentar la adopción de estas modalidades de provisión de infraestructuras, a pesar de que son mucho más complejas de llevarlas a la práctica.

La coyuntura es especialmente compleja. Pese al volumen de déficit público -que impide asumir nuevas obligaciones de gasto- es, sin embargo, necesario mantener un cierto nivel de construcción de obra pública para satisfacer necesidades públicas y por el efecto sobre el empleo. La pandemia del COVID19 ha hecho crecer las necesidades de actuación pública y los planes europeos y nacionales se vertebran sobre los procedimientos de colaboración público-privada.

\section{La colaboración público- privada como género y como especie}

El contexto que se ha descrito en el epígrafe anterior ha motivado una diversificación de las formas de provisión de infraestructuras ${ }^{(3)}$ $y$, especialmente, un impulso considerable a las formas de colaboración públicoprivada. Realmente, cuando se hace referencia a ella, se está planteando un abanico de posibilidades que en unos casos hacen referencia a modalidades diferentes de actuación por parte de los entes públicos. Esta es una constante en el derecho europeo desde hace años.

(1) Precepto que en este punto tiene una redacción similar a la del antiguo artículo 104 del Tratado de la Unión Europea.

(2) El documento fundamental publicado por Eurostat está constituido por el Manual del SEC 95 sobre el déficit público y la deuda pública.

(3) Véase la obra colectiva coordinada por Ruiz Ojeda, Ilamada "La financiación privada de obras públicas. Marco institucional y técnicas aplicativas". También la obra colectiva dirigida por Romero Álvarez titulada "Nuevas formas de financiación de proyectos públicos"; así como la de Ariño \& Almoguera, "Nuevo Derecho de las infraestructuras", o Valcárcel Fernández en "Ejecución y financiación de obra pública". Estudio de la obra pública como institución jurídico-administrativa, Herranz Embid, "Régimen general de las obras públicas", en la obra colectiva dirigida por González García, "Derecho de los bienes públicos", más sucintamente "Construcción, gestión y financiación de infraestructuras de interés general", en la obra colectiva dirigida por González García, llamada "Diccionario de Derecho de obras públicas y bienes públicos". 
Así, en el Libro verde sobre contratación pública se señala que el concepto de colaboración público-privada "en general se refiere a las diferentes formas de cooperación entre las autoridades públicas y el mundo empresarial, cuyo objetivo es garantizar la financiación, construcción, renovación, gestión o el mantenimiento de una infraestructura o la prestación de un servicio" (Comisión Europea, 2004, p. 3). En los documentos comunitarios se acostumbra a realizar una primera diferenciación entre las modalidades institucionales -que son las que dan nacimiento a un ente diferente- de las modalidades meramente contractuales.

Pero incluso dentro de estas últimas, no hay un único procedimiento que condense todas las modalidades de colaboración público-privada(4). Desde la estructurada concesión de obra pública a las modalidades atípicas, más propias realmente de colaboraciones público privada y que se recuerdan el título de aquella novela de Julio Cortázar, dado que se trata de efectivos "modelos para armar" (González, 2006, p. 22). Porque realmente lo que caracteriza como modalidad específica a estas formas de provisión de infraestructuras es su carácter atípico, funcional, constituyendo un género amplio de técnicas que están a disposición de contratista y Administración Pública (Villar, 2007, pp. 164 y ss.; Míguez, 2008, pp. 164 y ss.). De forma muy expresiva, Dipace ha señalado en Italia que con ello lo que se hace es "introducir el caballo de Troya de la atipicidad contractual en la ciudadela de la actividad contractual de los entes públicos" (Dipace, 2006, p. 15).

Realmente, cuando se introdujo un nuevo contrato típico en la Ley de Contratos del Sector Público, el contrato de colaboración entre el sector público y el sector privado(5), se estaba proporcionando una regulación básica para una forma de relación entre administración y contratista en la que la atipicidad, su flexibilidad, es precisamente su característica más relevante. $Y$, de hecho, como se puede apreciar de la regulación los contenidos imperativos no constituyen el núcleo básico de la regulación, sino que esta está constituida por una guía de elementos, para que las partes lo articulen de la mejor forma posible.

En esta línea, llama la atención que sea posiblemente el punto más relevante desde una perspectiva pública, el que motiva que se recurra a estos procedimientos, el efecto sobre el déficit no ha merecido ni siquiera un informe con ocasión de uno de los Reales Decretos Ley promulgados con medidas anticrisis. En todo caso, la promulgación de esta disposición en modo alguno impide que formas más atípicas, vinculadas a la gestión patrimonial, sigan resultando de aplicación; tal como se verá con posterioridad.

Pero si caracteriza algo la colaboración público-privada es su atipicidad. No hay en el ordenamiento español ningún contrato en la Ley de Contratos del Sector Público que tenga esta modalidad. Tampoco existe en la Ley de Patrimonio de las Administraciones Públicas. Pero, sin embargo, se siguen utilizando recogiendo los principios de libertad de pactos que se contemplan en el ordenamiento administrativo. Hoy, como señalé en otra ocasión, hay colaboración público-privada más allá de la Ley de Contratos del Sector Público(6).

\section{Los riesgos del uso de la colaboración público- privada}

En la resolución de las situaciones de crisis, el recurso de los gobernantes a fórmulas de Colaboración Público-Privada (se suele poner

(4) De hecho, bien podría señalarse que, en función de esta definición, hay diversas realidades detrás de la colaboración público-privada: (i) Por un lado, como mecanismo de financiación privada de construcción de obra pública, básicamente como el mecanismo por el cual los poderes públicos buscan el ahorro privado el cual se canaliza a través de cualquier tipo de instrumento ya sea éste créditos, emisiones de deuda, que son pagados por la Administración generadora del mismo; (ii) en segundo lugar, se puede estar haciendo referencia a que el gobierno busca financiación para compartir con el sector privado el riesgo de la inversión, lo cual nos lleva a que hay participación privada no sólo en la financiación sino también en la retribución y (iii) hay ocasiones en las cuales los poderes públicos buscan la participación privada a través de la construcción de las infraestructuras que son retribuidas por su utilización o disponibilidad de la misma, lo que hace que la financiación sea privada y la retribución en principio también. Un desarrollo de estas cuestiones puede verse en Juan Lozano y Rodríguez Márquez en su obra "La colaboración público-privada en la financiación de las infraestructuras y servicios públicos (una aproximación desde los principios jurídico-financieros)".

(5) La inclusión de este precepto ha motivado el interés de los autores. Así, véase Chinchilla, C. (2006). El nuevo contrato de colaboración entre el sector público y el sector privado. Revista Española de Derecho Administrativo, 132, 609 y ss.; García-Capdepón, P. (2005). El contrato de colaboración público-privado. Revista de la Función Consultiva, 3, 89 y ss. Y González, J. (2006). El contrato de colaboración público-privado. Revista de Administración Pública, 170, 7 y ss. Un recordatorio de algunos supuestos de colaboración público privada en el ámbito local los postula Arimany en "La colaboración público-privada en la provisión de infraestructura y equipamiento local".

(6) Colaboración público-privada, más allá de la Ley de contratos del Sector Público, en https://www.globalpoliticsandlaw.com/colaboracionpublico-privada-Icsp/. 
de moda. En principio, la idea puede no ser vista con malos ojos. Un particular asume el coste de construir la infraestructura y el riesgo de su explotación económica, se paga en función del uso y volverá a manos públicas al final de plazo estipulado en el contrato. Esta es la teoría.

Los modelos de colaboración público-privada no suelen ser operaciones simples. A partir de aquí comienzan los problemas, $y$, por ello, resulta imprescindible analizar muy cuidadosamente tanto el realizar una operación con esta fórmula jurídica como el articulado del contrato. La experiencia nos ha proporcionado demasiados ejemplos negativos, tanto por el coste, como por la mala calidad del servicio, por el deficiente control democrático y de ejecución e incluso por los efectos en clave de contabilidad nacional.

De hecho, el paso inicial, determinar que una prestación se realiza a través de una fórmula de PPP no suele venir precedida de un instrumento al que se recurre en otros países y que sirve para concretar sus ventajas para cada proyecto. Este estudio, que se denomina Public Sector Comparator, exige que se examine si la utilización de estos mecanismos aporta alguna ventaja añadida sobre lo que se podría obtener a través de su ejecución por parte del poder público a través de otros procedimientos. Con este instrumento lo que se debe extraer es el value for money que debe ser característico de los CPP. Si no se obtiene, hay medios más económicos y sencillos, entre ellos, el puro contrato de obras. Un dato esencial que se indica es que hay cierta ansiedad y poca reflexión a la hora de abordar los CPP.

Pero, a partir de este momento, los siete riesgos que pueden provocar los PPP se podrían estructurar del siguiente modo:

a) El riesgo del apoyo público y la dificultad del reintegro. Usualmente las operaciones de PPP tienen fórmulas de apoyo público tanto en los procesos de construcción de la infraestructura como en los de su explotación. En otro lugar, he relatado como este apoyo puede ser superior al dinero aportado por el concesionario con lo que el principio de que la mayor parte del riesgo de construcción y de explotación debe tenerlo el contratista no se da. Da igual la fórmula: si el Estado garantiza, como suele hacer, paga. Da igual si otorgó seguros de cambio y avales, rescató concesionarias en quiebra, confirió privilegios fiscales, entre otras cosas. Siempre paga... más.

b) El riesgo del rescate público. Una obra pública mal planificada, con un coste excesivo o con una inidónea asunción de riesgos por el contratista provoca que la entidad concesionaria entre en quiebra. El rescate de las autopistas de peaje españolas es un buen ejemplo que, además, se ha repetido en el tiempo. Aquí lo paradójico es que el Estado saldrá en su rescate con lo que no sólo perderá el reembolso del apoyo prestado, sino que deberá hacerlo con las entidades financiadoras. c) El riesgo del espejismo contable. En ocasiones, por impulso de Eurostat, las operaciones de PPP se han realizado con el objetivo de tener infraestructuras que no computen como deuda pública ni como déficit público, aunque hay que pagarlas. Eurostat fue muy expresivo sobre cómo evitar el coste en déficit y deuda de una infraestructura a través de un manual que estaba hecho pensando en la contabilidad de diseño para las operaciones de PPP. En la actualidad las cuentas públicas están llenas de este tipo de activos tóxicos, además se han hecho a muchos años vista.

d) El riesgo del mayor coste. Una operación de PPP, sea de la naturaleza que sea, resulta más cara que su realización a través de otros procedimientos. Hay dos razones que lo explican: el mayor tipo de interés que tienen que soportar las entidades privadas por comparación al Estado que nunca quiebra y, en segundo lugar, el beneficio industrial. Estamos hablando de un mayor coste que puede rondar el $25 \%$.

Es un elemento denunciado por el Tribunal de Cuentas europeo en su informe de 2018 "Asociaciones Público-privadas en la Unión Europea: deficiencias generalizadas y beneficios limitados". Un sobrecoste, manifestado esencialmente en "los modificados", esa gran lacra que hay en los proyectos de obra pública y que, en muchos casos, es consecuencia de una mala adjudicación de la obra por una rebaja de propuesta que impide la ejecución de la obra de una forma adecuada (y, que, además, puede ser una vía para la corrupción). Lo que no impidió, además, los retrasos en las obras.

Además, estos incrementos de costes de los proyectos suelen ser asumidos por el sector público, dado que el socio privado no suele asumir los riesgos económicos de los fallos de ejecución del proyecto. En España somos especialistas en el rescate de las autopistas de peaje, en una manifestación de la mala planificación de las obras y de que el socio privado no 
acaba asumiendo los riesgos económicos del proyecto, que recaen en manos públicas.

e) El riesgo de la Administración pública inadecuada. En el caso de nuestro país, carecemos en muchas ocasiones de un entramado institucional adecuado para la ejecución de los CPP. Un contrato de estas características precisa un conjunto de personas especialmente preparada, con experiencia en la materia, que permita extraer las consecuencias positivas de estos contratos. No nos podíamos beneficiar de cláusulas modelo, ni de orientación general ni nada parecido. El riesgo de que la Administración esté mal defendida en la planificación y gestión de los CPP es una realidad. Pero, esto también ocurre en el momento de la ejecución. Un PPP sin una Administración que controle al concesionario es un PPP ineficaz que regala dinero público. Los PPP requieren exhaustivos controles de calidad para determinar cuánto hay que pagar al contratista y para determinar el grado de satisfacción de los ciudadanos con los servicios. El contrato tiene que estar estructurado de este modo para garantizar el value for money tan típico de los PPP. Pero el papel de la Administración que está vigilante del contratista no termina aquí: cumple una función esencial para la determinación de cuáles son las necesidades básicas de la ciudadanía, lo que servirá para estructurar ulteriores contratos de forma adecuada.

f) El riesgo de la atipicidad legal. Las PPP son la consecuencia de que, en palabras de la Unión Europea, "son necesarias nuevas ideas, cláusulas innovadoras, así como la superación del concepto tradicional de "público" con el fin de fomentar esta tendencia a nivel comunitario". Constituyen un mecanismo abierto para que, en función de las necesidades públicas y las posibilidades de satisfacerlas por parte de los particulares, se organice una relación contractual compleja, de difícil control democrático. Y con ello aparece el riesgo para lo público.

g) El riesgo del contrato a largo plazo y las dificultades de reinternalización. No podemos olvidar un dato complementario: en los proyectos a largo plazo -que constituye una característica del modelo- hay un momento en el que el licitador deja de tener interés en su mantenimiento con el mismo nivel de calidad. La razón es bien sencilla: es posible no vaya a rentabilizar la inversión. La ausencia de unidades de seguimiento del proyecto contribuye a que su ejecución resulte, en consecuencia, manifiestamente mejorable.

\section{EI riesgo como elemento esencial de la valoración jurídica de los medios de construcción de infraestructuras}

El análisis jurídico de la naturaleza real de las formas de provisión de infraestructuras públicas depende en buena medida de la gestión del riesgo inherente a la construcción de la infraestructura. Ha de tenerse en cuenta que las restricciones en cuanto al déficit público han motivado por parte de las Administraciones públicas que se realicen operaciones de cierta ingeniería jurídicofinanciera con la finalidad de que determinadas operaciones no computen a los efectos del déficit. Por otra parte, es ya tradicional la preocupación de la Comisión Europea por la alteración de la relación entre el clausulado de los contratos y la modalidad contractual elegida por parte de la Administración pública ${ }^{(7)}$. Esta inquietud se proyecta habitualmente sobre la gestión del riesgo económico de la operación de construcción de infraestructuras, en la medida en que modalidades de colaboración público-privada que se analizan con cierto detenimiento acaban resultando meros contratos de obra con diferimientos en el pago.

El problema del reparto de riesgos es complejo, con esta y con casi cualquier normativa ${ }^{(8)}$; ya que afecta a numerosos

(7) De acuerdo con lo señalado con la Comunicación Interpretativa de la Comisión Europea 2000/C 101/02 "si los poderes públicos asumen las contingencias vinculadas a la gestión de una obra, asegurando, por ejemplo, el reembolso de la financiación, faltará el elemento de riesgo. En este caso, la Comisión considera que se trata de un contrato público de obras y no de una concesión. Además, si durante la duración del contrato o al término del mismo el concesionario recibe, directa o indirectamente (en forma de reembolso, de compensación, de pérdidas o de otra forma), una remuneración distinta de la correspondiente a la explotación, el contrato ya no podría ser tildado de concesión".

(8) Recordemos cómo con la legislación anterior había voces muy cualificadas que señalaban, que esa asunción del riesgo en proporción sustancial por el concesionario "no se refleja en el articulado de la ley, relativo a la concesión de obra públicas, incorporado a la LCAP. Y tampoco se refleja en el articulado la afirmación de la E. M. de que la Ley responde sin ambigüedades a las exigencias de la doctrina y conclusiones de la Comisión Europea, expuestas en su Comunicación Interpretativa 2000/C 121/02". GómezFerrer, R. (2003). El contrato de concesión de obras públicas. En R. Gómez-Ferrer (ed.), Comentarios a la Ley de contratos de las Administraciones Públicas ( $2^{\mathrm{a}}$ ed., p. 1103). Tirant Lo Blanch. 
factores que tienen un grado distinto de previsibilidad. Por un lado, hay que mantener el principio recogido en la LCSP de que el contrato se ejecute a riesgo y ventura del contratista y que, al mismo tiempo, se incentiven desde las Administraciones Públicas estas modalidades de construcción de infraestructuras, en las cuales la extensión temporal prolongada acostumbra a ser una característica a la par que un elemento que complica el análisis de riesgos. De hecho, hemos de recordar que la modalidad contractual en la que dispone de menor intensidad este principio es precisamente en una de las modalidades de colaboración público privada, de acuerdo con lo señalado en el artículo 197 la LCSP: "La ejecución del contrato se realizará a riesgo y ventura del contratista, sin perjuicio de lo establecido para el de obras en el artículo 214, y de lo pactado en las cláusulas de reparto de riesgo que se incluyan en los contratos de colaboración entre el sector público y el sector privado".

En todo caso, en el horizonte de la ejecución de un contrato de CPP no podemos olvidar que el principio que hay que satisfacer es este de la ejecución a riesgo y ventura del contratista.

En el ordenamiento jurídico español, a diferencia de lo que ocurre en Francia ${ }^{(9)}$, no está delimitado el porcentaje de participación pública en apoyo de la concesión administrativa. De hecho, examinando algunas de las concesiones de obra pública se observa que el reparto de riesgos estaba muy decantado en contra del ámbito público. La propia complejidad de estas modalidades contractuales dificulta en exceso la posibilidad de un control tanto de naturaleza política como económica. Hay, además, un factor que no es posible desdeñar cuando se aborda el problema de la gestión de los riesgos desde una perspectiva pública: en los procesos de configuración de las CPP suele estar muy involucrado el sector privado, incluso en la propia definición del objeto del contrato.

La dificultad del problema de gestión y configuración del riesgo al que se está haciendo referencia no es meramente teórica. El caso de la construcción del Metrosur por parte de una entidad dependiente de la Comunidad de Madrid, exterioriza cuál es el debate en el que nos encontramos. Una configuración técnico-jurídica compleja en el que participaron varias entidades dependientes de la Administración autonómica con la finalidad de no computar la construcción a efectos del déficit y que, sin embargo, la gestión del riesgo invalidó el objetivo propuesto; ya que tras la arquitectura jurídica, la Administración autonómica seguía siendo quien respondía de las consecuencias económicas del contrato ${ }^{(10)}$.
La decisión de Eurostat sobre la Autopista de Sanxeno(11), muestra cómo allá donde había formalmente una concesión, había que entender un contrato de obra precisamente porque no había una transferencia de riesgo al sector privado. Desde luego, la necesidad que tienen los entes públicos de reducir el déficit, la práctica de forzar la aplicación de los criterios del SEC95 ha hecho que:

los contables nacionales examinan cuidadosamente el contexto jurídico de las unidades y las operaciones para clasificarlas. Sin embargo, a veces es importante ver más allá de la forma jurídica de una unidad institucional o un flujo económico y transmitir la realidad económica. Esto puede aplicarse tanto a la clasificación de unidades como a la clasificación de flujos (Eurostat, 2002, p. 28).

Por ello, se puede señalar que algunas formas de contabilidad de diseño han llegado a las Administraciones Públicas.

Si el riesgo del cómputo en el déficit público puede provocar problemas de consideración de índole presupuestaria y puede motivar un replanteamiento de la política pública de inversiones, los peligros de naturaleza económica no son menos reales. Tomo las palabras de Ruiz Ojeda, que resultan en este lugar muy expresivas de los problemas teóricos y reales que se han planteado con el respaldo público a la construcción de infraestructuras por los particulares; y lo que es expresión de cómo la historia se repite:

No hablo de conjeturas: las autopistas españolas son el mejor antídoto contra la elucubración. Y quien garantiza, paga. EI Estado garantizó, y fue él quien pagó, y sigue pagando: otorgó seguros de cambio y avales, rescató concesionarias en quiebra, confirió privilegios fiscales, entre otras cosas. El que diga que sólo con garantías públicas se logrará la implicación del capital privado en la financiación de infraestructuras se equivoca rotundamente. Con garantías públicas de tal guisa lo que se consigue es dar un largo rodeo, con un resultado injusto e ineficiente, y todo para camuflar lo que desde el principio

(9) En Francia está establecido por el Consejo de Estado un tope máximo del 70\% de aportación pública para que se pueda hablar de concesión de obra pública. Tomo el dato de Martín, P. (2003). Régimen económico-financiero de la concesión de obra pública. En Comentarios a la nueva Ley 13/2003, de 23 de mayo, reguladora del contrato de concesión de obras públicas. Editorial Civitas.

(10) Sobre este contencioso, véase el interesante artículo de Martínez, J. (2005). Hacia la construcción de un Derecho administrativo financiable. Crónica del caso MINTRA". Revista de Administración Pública, 167, 369 y ss.

(11) Decisión de Eurostat de 3 de junio de 2008, sobre la Autovía del Salnés, Tramo enlace con la PO 531-Sanxenxo. 
era claro como la luz del día: que la Administración respondía íntegramente, o sea, el riesgo y ventura de la entidad pública concedente. Para este viaje no se necesitan tales alforjas (Ruiz, 2002, p. 176).

Conclusiones que sirven para las autopistas de los años setenta y también para las radiales de Madrid hechas en el periodo 1996/2004, y cuyo análisis económico se efectuó con unas previsiones que no resistían ningún análisis de razonabilidad, ya que los problemas no se vinculan a la crisis sino al propio incremento de los precios del suelo fruto de la nefasta política urbanística de la época y que está en la raíz de las peculiaridades españolas de la crisis económica. Por tanto, como se puede ver, el problema de la ponderación de los riesgos es una cuestión vital dentro del funcionamiento de las Administraciones Públicas. Reflexiones, en fin, que tienen su manifestación más clara en el rescate de las autopistas de peaje otorgadas en la época del Gobierno Aznar.

De hecho, en este contexto tan favorable a la introducción de las modalidades de colaboración público-privada, la propia Comisión europea ha insistido en los riesgos que plantean para las Administraciones públicas. Concretamente, ha indicado que "las APP son un instrumento atractivo, en pleno auge en muchos sectores, pero cuyo éxito depende de la presencia de ciertos factores o condiciones: proyectos de dimensión reducida, proyectos cuya remuneración y riesgos son fáciles de calcular, autopistas, puentes o aeropuertos. Pueden resultar igualmente útiles cuando la aportación privada permita maximizar los resultados y controlar mejor los costes en comparación con un proyecto similar gestionado por el sector público. Ahora bien, esta solución suele tener repercusiones en el terreno de los costes, que a menudo suelen ser superiores a los de una financiación íntegramente pública, a causa del coste de las transacciones -en particular los costes ligados a la determinación, distribución y cobertura de los riesgos- y de los capitales, mayor para los inversores privados. Está claro que el recurso a las APP no se puede presentar como una solución milagro para el sector público, agobiado por las presiones presupuestarias. Nuestra experiencia demuestra que una APP mal preparada puede dar lugar a costes muy elevados para el sector público"(12).

He tomado, a partir de ahora, los problemas derivados de la gestión del riesgo en relación con el cumplimiento de las obligaciones de estabilidad presupuestaria. Sin lugar a duda, esta es una consecuencia secundaria de la transferencia de riesgos, pero tiene la suficiente entidad como para que nos permita el examen de otras cuestiones de régimen de los contratos de colaboración público-privada.

\section{Riesgo en la colaboración público-privada y estabilidad presupuestaria}

Las fórmulas de colaboración público-privada han encontrado su razón fundamental de existencia para las Administraciones públicas en el cumplimiento del principio de estabilidad presupuestaria. La razón básica que justifica esta vinculación deriva del hecho de que las modalidades de colaboración público privada permiten la transformación de las partidas presupuestarias para que no supongan necesidades de financiación por parte de los entes públicos, ya sea porque se modifica la partida presupuestaria a la que se carga la operación, figurando como servicio en lugar que como adquisición de bienes o bien porque el que asume el riesgo es otra entidad, como ocurre con las sociedades estatales de obras públicas. Es, además, un tipo de procedimiento que ha sido de alguna forma incentivado desde la Oficina Estadística de la Unión Europea, Eurostat, que de forma un tanto sorprendente ha aprobado una serie de documentos en donde se proporciona una guía para la acción en relación con el reparto de riesgos ${ }^{(13)}$.

Todo ello, además, con el espejo de la conocida decisión sobre la sociedad del Gobierno Federal Austriaco Bundesinmobilliengesselschaft -resolución conocida usualmente como caso BIG-, que constituye el modelo de los entes públicos europeos para mantener un elevado nivel de construcción de infraestructuras sin consolidación en el déficit público. Se trataba de una operación compleja en donde se encomendó a la sociedad BIG la gestión del patrimonio inmobiliario del Estado, con el encargo de acometer su remodelación para ponerlo a disposición del Estado con un arrendamiento que se abonaría de acuerdo con precios de mercado, asumiendo la sociedad el riesgo de un coste superior a lo asignado por el Gobierno para cumplir esta función. En todo caso, en estas situaciones procede de un estudio exhaustivo de cuáles

(12) Comunicación de la Comisión de 23 de abril de 2003 sobre Desarrollo de la red transeuropea de transporte: Financiaciones innovadoras. Interoperabilidad del telepeaje.

(13) El documento fundamental publicado por Eurostat está constituido por el Manual del SEC 95 sobre el déficit público y la deuda pública. 
son las prestaciones características de la relación pactada y cuál ha sido el grado de transferencia del riesgo económico del contrato al socio privado, lo que se ha tenido que producir en una proporción sustancial.

De hecho, esta tendencia a la utilización de las fórmulas de los CPP y, en particular, la tendencia a la utilización imaginativa de los negocios jurídicos por parte de los entes públicos ${ }^{(14)}$ se ha traducido en que el propio Eurostat insista en la necesidad de un estudio exhaustivo de las figuras empleadas por parte de las autoridades nacionales encargados de la verificación del déficit público. Concretamente, se señala que:

los contables nacionales examinan cuidadosamente el contexto jurídico de las unidades y las operaciones para clasificarlas. Sin embargo, a veces es importante ver más allá de la forma jurídica de una unidad institucional o un flujo económico y transmitir la realidad económica. Esto puede aplicarse tanto a la clasificación de unidades como a la clasificación de flujos" (Eurostat, 2002, p. 28).

Actividad de las entidades nacionales que ha de aplicar la doctrina Eurostat que está recogida en sus manuales, aunque no por ello, el grado de transparencia ni en cuanto a los criterios ni en cuanto a los procedimientos de aplicación es suficiente, como se mostró en el caso de la construcción del Metrosur en la Comunidad de Madrid por parte de Mintra, entidad pública empresarial de la propia Comunidad.

El punto de partida está constituido por el hecho de que en el documento clave del régimen de cómputo del déficit, el SEC 2010, las operaciones del CPP se describen como:

contratos complejos, a largo plazo, entre dos unidades, una de las cuales es normalmente una sociedad (o un grupo de sociedades, privadas o públicas) denominada operador o socio, y la otra normalmente una unidad de las administraciones públicas denominada concedente. Las APP suponen un gasto de capital importante para crear o renovar activos fijos por parte de la sociedad, que después opera y gestiona los activos para producir y ofrecer los servicios bien a la unidad de las administraciones públicas o al público en general en nombre de la unidad pública (20.227).
Desde este punto de vista, las relaciones jurídicas tendentes a la construcción de infraestructuras públicas reciben, desde el punto de vista contable, la consideración de formación bruta de capital fijo. En principio, lo que hay que diferenciar es, siguiendo lo dispuesto en el Plan de Estabilidad y Crecimiento, cuándo esas operaciones afectan a las necesidades de financiación de los entes públicos, con la consecuencia del cómputo para el déficit. En principio, si se recurre a las formas tradicionales de construcción de infraestructuras -esto es, al contrato de obra pública- computarían la cuantía de la financiación en la contabilidad de la Administración contratante y tendría el efecto consecuente sobre el incremento déficit público de dicho ente público y, por ende, del Estado afectado. Por tanto, de lo que se trata es de examinar en qué condiciones no se va a producir la consolidación contable.

En principio, en las operaciones de cooperación público privada de carácter puramente contractual, el análisis de cuándo no se computa a efectos del déficit público parte del principio de que lo relevante no es la forma jurídica que se esté utilizando sino la naturaleza de los flujos económicos, sobre todo si tenemos en cuenta que las CPP presentan numerosas modalidades con diferentes prestaciones, lo que incluso ha motivado la adaptación de la doctrina general de Eurostat ${ }^{(15)}$ en aras de un control más efectivo de estas operaciones de cooperación público privada. Aunque la exteriorización de esta doctrina ha dado pie a que su uso suponga un incentivo para la utilización de

(14) Con la claridad que le caracteriza, López-Muñiz (1997) ha afirmado que "es cosa bien sabida que si en algo son expertos en la Comisión Europea es precisamente en no dejarse confundir con la heterogeneidad de formas y técnicas de cobertura que son tradicionales de los diferentes Estados o que éstos crean con los más diversos fines" (p. 73).

(15) News Release 18/2004. De hecho, la adopción de la decisión es la consecuencia del desarrollo imaginativo de las fórmulas de asociación público-privada: "las colaboraciones público-privado vienen desarrollándose desde hace bastantes años en el seno de la Unión Europea. Estas fórmulas de promoción de infraestructuras pueden adoptar diversas formas, incluyendo las tradicionales concesiones administrativas que normalmente no consolidan en el balance de la Administración. Recientemente, se han venido realizando nuevas e innovadoras fórmulas de colaboración en algunos países miembros, y se estima que esta tendencia continúe e incluso se acreciente como consecuencia de la necesidad de incrementar la eficiencia del gasto público y la calidad global de los servicios públicos. La Iniciativa de Crecimiento de la Unión Europea, aprobada por el Consejo Europeo de 2003, establece como uno de los objetivos prioritarios el recurso a estas innovadoras fórmulas de colaboración público-privada en la promoción de infraestructuras. Si bien la Oficina Estadística de la Comisión, Eurostat, no examina los motivos, la racionalidad y eficiencia de estas relaciones, tiene que proporcionar guías claras para su tratamiento en contabilidad nacional, para observar su impacto en los gatos generales del sector público. Más aún, una parte importante de la misión de Eurostat es asegurar la homogeneidad de las estadísticas gubernamentales en todos los Estados Miembros -incluidos los 10 Miembros que están en proceso de incorporaciónde tal manera que el déficit y las estadísticas de deuda sean íntegramente comparables de acuerdo con el sistema SEC 95. 
estas figuras, configurada al modo que la Oficina Estadística Europea ha estructurado.

La determinación de la naturaleza de los flujos económicos pasa a ser un elemento central del examen, ya que es lo que permitirá delimitar si nos encontramos con las que se consideran transferencias financieras o si, por el contrario, son catalogables como no financieras. La razón que motiva esta diferenciación es clara y está en el propio Protocolo sobre el déficit público, tal como ha señalado el propio Eurostat:

Dado que, en el Protocolo sobre el procedimiento aplicable en caso de déficit excesivo, el déficit se ha definido como la necesidad de financiación del sector administraciones públicas, se produce una asimetría entre el tratamiento estadístico de los activos no financieros y el de los activos financieros. Las variaciones de los activos no financieros (cuando se deben a operaciones) se registran en la cuenta de capital. Por lo tanto, modifican la capacidad o necesidad de financiación, que es el saldo de la cuenta de capital. Por el contrario, las variaciones de los activos financieros -registradas en la cuenta financiera- no modifican dicho saldo (excepto en el caso de las variaciones unidireccionales, como la asunción de deudas o la cancelación deudas, si la variación de los pasivos se compensa mediante una transferencia de capital) (Eurostat, 2002, p. 30).

De hecho, el auge y caída de algunas modalidades contractuales ha estado determinada por su consideración como transferencia financiera o no financiera.

El factor determinante para la desconsolidación, que ya se vio que jugaba un papel central en las CPP, consiste en que se pueda comprobar que se ha producido en la relación jurídica una transferencia suficiente de riesgo al contratista, de tal manera que la mayor parte de éstos sean asumidos por la parte externa a la Administración Pública. De hecho, así lo ha afirmado Eurostat después de examinar la realidad que se está abriendo: "el análisis de los riesgos asumidos por las partes contractuales constituye el elemento fundamental a la hora de clasificar el activo afecto al contrato para asegurar la correcta contabilidad del impacto sobre el déficit público de este tipo de asociaciones" (Eurostat, 2004, p. 9). Realmente, en el análisis tiene que romperse una especie de presunción de que nos encontramos ante un bien público que, por consiguiente, la operación económica que se está realizando se consolida en el cómputo del déficit público, tal como viene señalando Eurostat: "en las cuentas nacionales, los activos afectos a un contrato a largo plazo entre una unidad administrativa y una unidad de mercado solamente pueden considerarse activos no públicos si existe una fuerte evidencia de que es el socio privado el que soporta la mayor parte de los riesgos inherentes a la ejecución del contrato" (Eurostat, 2004, p. 9).

Como es fácil entender, este pacto en relación con el reparto de riesgos constituye un elemento básico del contrato para el cual se han arbitrado procedimientos específicos. Sin embargo, no podemos olvidar que las formas de CPP se ejecutarán a riesgo y ventura de los contratistas, lo que supone que en principio no se puede proceder a una imputación de riesgos a la Administración superior a lo que resulta razonable. Si ocurriera, nos encontraríamos en una alteración de la naturaleza del contrato, tal como ocurre con la relación entre la concesión de obra pública y el contrato de obra. Tal como ha señalado Gómez-Ferrer, aludiendo al problema del reparto de riesgos en la concesión de obras lo que es perfectamente extrapolable a este contrato, "lo importante es poner ahora de relieve que el concesionario asume el riesgo de financiación de la construcción y explotación de la obra a partir de las bases establecidas en el contrato. Y que el "mínimo" no deberá ser tan alto que excluya el riesgo, sino que habrá de ser el adecuado para que una empresa "eficiente" asuma el riesgo de financiar la construcción y explotación de la obra"(GómezFerrer, 2003, p. 1112); ya que si no fuera así nos podíamos encontrar con que "la verdadera naturaleza de este caso es la de un contrato de obra pública con un sistema de retribución por la Administración aplazado en el tiempo y calculado en función del uso de la infraestructura en forma similar al de la concesión", en el que el "coste va a cargo de la Administración y su abono en la forma expuesta es una obligación de la Administración" (Gómez-Ferrer, 2003, p. $1105)^{(16)}$.

(16) En un sentido similar, la Comunicación Interpretativa 2000/C 121/02, de 29 de abril de 2000, ha señalado que "para la comisión, estaremos en presencia de contratos públicos de obras en la acepción del Derecho comunitario cuando el coste de la obra vaya a cargo principalmente del órgano de contratación y el contratista no reciba su remuneración a través de derechos percibidos directamente de los usuarios de la obra. El hecho de que la Directiva permita que el derecho de explotación vaya acompañado de un precio no altera este análisis. Se trata de una hipótesis que se da en la práctica. Puede ocurrir, por ejemplo, que el Estado asuma parcialmente el coste de explotación a fin de aminorar el precio que debe pagar el usuario (práctica de los precios sociales). Esta intervención puede revestir distintas modalidades (importe garantizado a tanto alzado, importe fijo pero pagado en función del número de usuarios, etc.). estas intervenciones no cambian necesariamente la naturaleza del contrato si el precio pagado cubre sólo una parte del coste de la obra y de su explotación. 
Por último, desde el punto de vista de la consolidación también conviene deslindar asociaciones erróneas: hay pagos presupuestarios que no provocan la consolidación contable, debido a la partida del presupuesto de la que proceden -gastos corrientes, que es lo que hace que un arrendamiento no compute a efectos de déficit-. En ciertas ocasiones, las actuaciones de una sociedad mercantil pública no computan a efectos de déficit público y en otras el apoyo público a una concesión de obra pública es de tal magnitud o naturaleza que tiene el efecto de que se consolide. $Y$ obviamente, la consolidación o desconsolidación de una obra en el déficit público a efectos de la estabilidad presupuestaria, nada tiene que ver con el pago de la obra: consolide o no ésta en el déficit hay que pagarla, a través de los mecanismos presupuestarios o extrapresupuestarios que haya previsto la Administración en el momento de su planificación.

\section{La transferencia de riesgos al contratista de la Administración pública}

El aspecto central aparece la transferencia de riesgos fuera de la Administración, a la otra parte del contrato. Ciertamente, no es sólo un problema del análisis del déficit público, sino que afecta a la propia naturaleza de estas figuras de colaboración público-privada ${ }^{(17)}$ ya que si no se procediera a la transferencia de riesgos a las entidades que colaboran con las Administraciones públicas para la realización de la infraestructura, la naturaleza del contrato debería ser otra. De hecho, así lo ha afirmado Eurostat después de examinar la realidad que se está abriendo: "el análisis de los riesgos asumidos por las partes contractuales constituye el elemento fundamental a la hora de clasificar el activo afecto al contrato para asegurar la correcta contabilidad del impacto sobre el déficit público de este tipo de asociaciones" (Eurostat, p. 9). Es, en definitiva, lo que permite diferenciar un contrato de obra simulado de otra figura jurídica.

En la actualidad se trata de un problema de notable importancia en la medida en que se están favoreciendo la cooperación pública y privada, hay mayor control sobre el cumplimiento de los criterios del déficit público y, en consecuencia, hay una necesidad suplementaria de desarrollar fórmulas imaginativas para la plasmación de proyectos que tendrían un acomodo fácil a través de los tres contratos típicos, especialmente el de obra pública.

En este contexto, el análisis de las operaciones está girando sobre los riesgos económicos que surgen de ella para poder preceder a una adscripción que sea económicamente real. Ha de tenerse en cuenta, en este sentido, que en el sistema SEC 2010 no resulta posible efectuar una división en dos contabilidades -la pública y la privada- de la operación, en función del volumen de riesgos que asuma cada una de las partes contratantes; lo que hace que, de forma global, una operación -en su conjunto sólo será posible clasificarla dentro o bien de las cuentas del ente público o bien en las de la unidad institucional de mercado. $Y$ casi podría decirse que en este momento hay una presunción, razonable por otra parte, de que han de consolidarse en la contabilidad de la Administración Pública. Bien puede afirmarse, en este sentido, que "la evolución que se observa en los criterios de Eurostat, que cada vez son más detallados y acotan mejor el perfil de las entidades a incluir en el sector Administraciones Públicas, pone de manifiesto la dificultad creciente de ensayar fórmulas creativas para soslayar los límites de déficit y endeudamiento impuestos por Maastricht" (Pina \& Torres, 2004, p. 44), aunque acaso no se deba ser todo lo optimista que quieren estos autores si se conoce un poco el funcionamiento diario de los entes públicos.

En efecto, en este punto, Eurostat viene aplicando un principio que parece que tiene asumido con claridad: "en las cuentas nacionales, los activos afectos a un contrato a largo plazo entre una unidad administrativa y una unidad de mercado solamente pueden considerarse activos no públicos si existe una fuerte evidencia de que es el socio privado

(17) Recordemos que, en relación con el debate entre la concesión de obra pública y el contrato de obra la Comunicación Interpretativa de la Comisión Europea 2000/C 101/02 "si los poderes públicos asumen las contingencias vinculadas a la gestión de una obra, asegurando, por ejemplo, el reembolso de la financiación, faltará el elemento de riesgo. En este caso, la Comisión considera que se trata de un contrato público de obras y no de una concesión. Además, si durante la duración del contrato o al término del mismo el concesionario recibe, directa o indirectamente (en forma de reembolso, de compensación, de pérdidas o de otra forma), una remuneración distinta de la correspondiente a la explotación, el contrato ya no podría ser tildado de concesión. En este caso, la compatibilidad de la financiación adicional tendría que ser analizada a la luz del conjunto de disposiciones pertinentes de Derecho comunitario". Esta es una conclusión perfectamente extrapolable a las restantes fórmula de colaboración público privada. 
el que soporta la mayor parte de los riesgos inherentes a la ejecución del contrato" (Eurostat, 2004, p. 8). En este sentido, los mecanismos de control por parte del ente público sobre el particular y, sobre todo, la previsión contractual de imposición de sanciones, que deben tener un cierto automatismo y surtir un efecto relevante sobre el resultado de la explotación -lo que impide las sanciones simbólicas- son datos que contribuyen a la idea de que se ha producido un traspaso real de los riesgos de la operación.

Más aún, la asunción de riesgos por parte del particular debería ser, si aplicáramos los principios del SEC 2010 desde la más absoluta ortodoxia, total, aunque Eurostat ha considerado que puede resultar normal que la Administración pueda asumir ciertos riesgos, como ocurre con los acontecimientos muy excepcionales o en el caso de aquellas actuaciones administrativas que modifiquen las condiciones del contrato. En todo caso, lo que se pretende evitar es que tras una apariencia de que es el contratista de la Administración el que asume las consecuencias sea el propio ente público el que contrae la mayor parte de las obligaciones.

Una determinación genérica de los riesgos inherentes al contrato resulta ciertamente complicada. Por ello, en aras de facilitar la comprobación de la realidad económica del contrato, se ha ampliado entre el SEC 95 y el SEC 2010 de tres a cinco las modalidades de riesgo que han de ser asumidas por el contratista (SEC 20.283)(18):

a) Riesgo de construcción, que incluye los rebasamientos en los costes, la posibilidad de costes adicionales derivados de retrasos en la entrega, el incumplimiento de condiciones o códigos de construcción, y los riesgos ambientales y de otros tipos que exijan pagos a terceros.

b) Riesgo de disponibilidad, que incluye la posibilidad de costes adicionales, como los de mantenimiento y financiación, y las sanciones soportadas porque el volumen o la calidad de los servicios no cumple las normas especificadas en el contrato.

c) Riesgo de demanda, que incluye la posibilidad de que la demanda de los servicios sea mayor o menor de la esperada.

d) El riesgo de valor residual y obsolescencia, que incluye el riesgo de que el activo sea inferior a su valor esperado al final del contrato y el grado en que las administraciones públicas tienen opción a adquirir los activos.

e) La existencia de financiación del garante o de concesión de garantías, o de cláusulas de rescisión ventajosas sobre todo en caso de rescisión a iniciativa del operador.

No obstante, se sigue manteniendo la regla de que "los riesgos y beneficios corresponden al operador si el riesgo de construcción y la demanda o los riesgos de disponibilidad han sido transferidos de manera efectiva. La financiación mayoritaria, las garantías que cubren la mayoría de la financiación percibida, o las cláusulas de rescisión que prevén un reembolso mayoritario del proveedor de la financiación en caso de rescisión a iniciativa del operador provocan la ausencia de una transferencia efectiva de cualquiera de estos riesgos" (SEC 20.284).

Esta realidad se va a aplicar incluso en los casos en los que la asunción de riesgos no es directa. En efecto, en el caso en que la participación pública suponga que la Administración ostenta la condición de garante de una parte relevante del riesgo -aunque sea para obtener mejores costes de financiación en los mercados y mejor calificación de los riesgos-, en ese caso, la operación se deberá consolidar en su balance. Eurostat lo afirma de este modo:

En algunos casos, la garantía de una deuda puede hacer que la deuda del socio se clasifique como deuda pública, como ocurre cuando existen disposiciones legales por las cuales se transmita a la Administración la totalidad o parte del servicio de la deuda o en los supuestos en donde nos encontramos con la incapacidad evidente por parte del socio para atender a sus obligaciones de pago de la deuda (Eurostat, 2004, p. 12).

De igual manera, el destino final del inmueble son tenidos en cuenta como elementos indirectos para determinar si hay o no una transferencia de riesgos al particular que colabora con la administración, de tal manera que el coste de la infraestructura se consolidaría en las cuentas públicas siempre que la Administración se haga con el activo a la finalización del contrato y el precio determinado de ante mano sea superior al valor del bien o pese a ser inferior los pagos realizados regularmente hayan alcanzado un valor similar al de éste. Y obviamente nos encontramos ante una problemática muy particular en los supuestos en los cuales la Administración contrata con una sociedad de

(18) Sobre esta cuestión específica se puede consultar el estudio de las profesoras Macho Pérez \& Marcos Peña (2014). El impacto de las colaboraciones público-privadas en los niveles de déficit y deuda públicos: análisis de los criterios de Eurostat. Revista de Administración Pública, (194). 
capital enteramente público, creada por dicha administración pública para el tipo de actividades como la que se pretenden realizar y que, por su especificidad, lo abordaremos cuando se desarrolle el capítulo relativo a la construcción a través de una sociedad mercantil pública.

Los únicos riesgos que no son tenidos en cuenta en el análisis son los que no están vinculados al activo que se va a construir y que se pueden separar del contrato principal, lo que condiciona, por ejemplo, las aportaciones públicas para la construcción de la obra y, de igual manera, las garantías públicas, tal como veremos con posterioridad en los capítulos sucesivos. Es por ello por lo que las operaciones de cooperación público-privado no suelen resultar sencillas $\mathrm{y}$, asimismo, hay una voluntad de difuminar los riesgos fuera del ámbito público. En todo caso, en los capítulos siguientes aparecerán algunas cuestiones puntuales que no conviene señalar en este momento dado que quedarían difuminados por afectar a aspectos concretos de modalidades específicas.

En este momento conviene que se analicen las diversas modalidades de riesgo que ha configurado Eurostat, que han de ser estudiadas para un adecuado engarce en la contabilidad del ente público o del particular y que, como se ha señalado con anterioridad son riesgos de construcción, riesgos de disponibilidad y riesgos de demanda.

Aunque pueda parecer que con ello nos introducimos en una perspectiva meramente contable, para determinar los efectos en contabilidad nacional de la construcción de una infraestructura, nos está llevando al análisis de cómo se aplica el principio de riesgo y ventura de la contratación pública, que el artículo 199 LCSP modula para una de las modalidades de colaboración público privada: "La ejecución del contrato se realizará a riesgo y ventura del contratista, sin perjuicio de lo establecido para el de obras en el artículo 214, y de lo pactado en las cláusulas de reparto de riesgo que se incluyan en los contratos de colaboración entre el sector público y el sector privado" (artículo 199 LCSP).

\section{Riesgos de construcción}

La primera modalidad de riesgo que ha de ser analizada es el denominada riesgo en la construcción. El riesgo de construcción, tal como ha sido definido por Eurostat, "cubre aspectos que afectan al estado inicial del acto. En la práctica cubre acontecimientos tales como retrasos en la entrega, incumplimiento de criterios especificados, costes significativos, deficiencias técnicas y factores externos negativos -incluidos los riesgos ambientales-, que conllevan pagos indemnizatorios a terceros" (Eurostat, 2004, p. 9). Obviamente esto se aplica tanto a los supuestos en los que las consecuencias económicas de los riesgos los asume el ente público como en aquellos otros en los que el contrato está planteado de tal manera que hay un sobrecoste para la Administración para hacer frente a estos gastos hipotéticos.

Para que estos riesgos no computen en la contabilidad de un ente público han de haber sido transferidos al colaborador de la Administración, cuestión para cuya comprobación se procede a una subdivisión de los riesgos que se producen en el momento de la construcción del bien por parte del particular. En todo caso, sí conviene afirmar que esta transferencia de los riesgos implica que la Administración ha de efectuar pagos en circunstancias muy concretas En relación con esta modalidad de riesgos, como se ha afirmado, se ha de proceder a una transferencia real de los mismos al particular que colabora con la administración de tal manera que los pagos que efectúe la Administración deben ser la consecuencia de un estado de los activos que lo requieran. Así, en condiciones normales un socio particular de la Administración no debería aceptar únicamente aquellos riesgos de construcción cuando las exigencias administrativas resulten inusuales, de tal manera que pueden aceptar a la viabilidad comercial del producto o cuando a través del comportamiento del ente público se modificación las especificaciones durante el proceso constructivo o se alteran requisitos usuales.

Los riesgos del proceso de construcción $y$, por ende, el coste de asunción del proyecto debe ser asumido por el particular. De este modo, la realización de pagos anticipados por parte de la Administración, que no sean la consecuencia de la comprobación de la calidad de las obras sólo podrá ser admitidos en el supuesto de que tengan reconocida de forma expresa la naturaleza de pagos a cuenta, de lo que se podría derivar, en su caso, un saldo positivo para la Administración en el momento de la liquidación definitiva. A una conclusión similar se llega cuando los pagos los efectúa la Administración para cubrir sistemáticamente cualesquiera costes adicionales, sea cual fuere su justificación, dado que esto evidencia que los riesgos reales de ejecución del proyecto no han sido asumidos por parte del particular, sino que siguen estando en manos de la Administración. 
Los pagos no deben servir, asimismo, para el abono de cualesquiera costes adicionales que hayan surgido en el desarrollo del contrato, ya que esto evidenciaría una mala previsión por el socio privado y, paralelamente, una asunción de riesgos por parte de la Administración; por lo que han de ser abonados por el contratista de la Administración pública, nunca por ésta. Eurostat afirma, en este sentido, de forma clara que "un punto importante es que la Administración no deberá estar obligada a efectuar ningún pago que se derive de un incumplimiento en la gestión de la construcción por parte del socio privado, bien como proveedor directo o únicamente como coordinador/supervisor" (Eurostat, 2004, p. 15). Esta doctrina, por ejemplo, es especialmente relevante a la hora de estudiar las posibilidades de apoyo administrativo a los concesionarios por aumentos de gastos de expropiación, supuesto que desde luego no resulta desconocido en nuestro país, ya que es una de las principales reivindicaciones en relación con las autopistas radiales de los alrededores de Madrid y que, por aplicación de la antedicha doctrina, el Estado no puede asumir.

Por último, conviene recordar que sí resulta admitido en el sistema contable europeo que la Administración puede asumir aquellos riesgos que se deriven de acontecimientos exógenos imprevistos, que estén fuera de la cobertura normal que proporcionan las compañías de seguros para la construcción de las infraestructuras y que, obviamente no debe confundirse con la idoneidad del "diseño" de los activos, ya que en este último supuesto nos encontramos ante un riesgo de construcción, derivado de la deficiente planificación del proyecto y tampoco ante problemas derivados de la falta de análisis previos ni de falta de previsión del contratista. Han de ser supuestos, en consecuencia, totalmente imprevisibles.

Estas reglas que se acaban de exponer sobre los riesgos de la construcción podrían ser matizadas por Eurostat siempre que se trate de proyectos para el desarrollo de productos novedosos en los que exista un desarrollo de una labor importante de investigación y desarrollo, o de innovación tecnológica, en los cuales la participación de los particulares resulta muchísimo más complicada precisamente por el incremento de riesgos. Frente a esta admisibilidad de ciertos pagos para el fomento de la investigación científico-técnica, los criterios resultan más rígidos en los casos en los que nos encontremos ante actividades más convencionales, que carecen del componente de investigación.

\section{Riesgos de disponibilidad de la infraestructura}

\subsection{Desarrollo general de la transferencia de riesgos de disponibilidad}

En segundo lugar, para determinar si se ha de operar la consolidación en la contabilidad de una Administración pública de una operación, se ha de proceder al análisis de los denominados riesgos de disponibilidad. De acuerdo con lo señalado por Eurostat, este tipo de riesgo está constituido por los que:

hacen referencia a aquellos casos en los que, durante la explotación del activo, se reclama la responsabilidad del socio porque a causa de una gestión deficiente, el volumen de servicios es inferior al contractualmente convenido o su nivel de calidad no satisface la convenida en el contrato (Eurostat, 2004, p. 9).

Para determinar cómo se han de computar este tipo de riesgos ha de recordarse que los pagos que en estas operaciones efectuaría la Administración serían pagos periódicos en contraprestación por la explotación de una obra o la prestación de un servicio o por ambos, pero que en todo caso han de ser reales ${ }^{(19)}$. Precisamente por ello, como ha señalado EUROSTAT, han de afectar al activo principal y no a alguno de los contratos complementarios, que estén vinculados a él, pero que no lo tengan como su objeto principal ${ }^{(20)}$, como ocurriría, por ejemplo, en un contrato para la construcción de un hospital pero que llevara anejos los servicios de lavandería, que obviamente nada tienen que ver con el inmueble y que de hecho suelen ser redefinidos en alguna de sus cláusulas varias veces durante el periodo de la vida del contrato sobre el inmueble.

Desde esta perspectiva, lo que exige Eurostat para que no se contabilice en la contabilidad del ente público que ha

(19) Con independencia de que con posterioridad se aluda a este problema con mayor detenimiento, pueden verse los Informes de la Junta Consultiva 61/03, de 12 de marzo de 2004 y 70/04, de 11 de marzo de 2005, en los cuales se hace referencia a problemas con la utilización de ciertas modalidades contractuales, precisamente porque no había realmente un servicio ni había transferencia de riesgos al particular, sino que se trataba de contratos de obra disfrazados.

(20) Esto lo señaló Eurostat en su decisión de 11 de febrero de 2004 en donde hizo una concreción de los riesgos que podían ser incluidos entre los que se diferían al particular a efectos de que no computara la operación en la contabilidad pública. Allí, señaló que "no se deben considerar riesgos que no estén relacionados con el activo y que puedan ser completamente separados del contrato principal como es lo que ocurre cuando el contrato puede ser totalmente renegociado periódicamente y sujeto a deducciones que no dependen significativamente de los activos principales" (p. 2). 
adjudicado el contrato es que el bien objeto del contrato está disponible para el servicio que quiere prestar la Administración pública en cantidad suficiente y con la calidad adecuada para que el servicio esté adecuadamente prestado. Paralelamente, ante supuestos de incumplimiento por parte del contratista, lo que resulta exigible para la desconsolidación contable es que éste responda como hace cualquier empresario privado ante este tipo de situaciones. $\mathrm{O}$, planteada la cuestión desde el punto de vista de los abonos que hace el ente público al contratista, Eurostat ha indicado que "los pagos por la Administración dependerán del nivel efectivo de disponibilidad asegurado por el cliente privado durante un período de tiempo determinado" (Eurostat, 2004, p. 15).

En todo caso, en el momento de la firma del contrato deben quedar pactadas las cantidades máximas que pueden cobrar el contratista durante toda la vida de la colaboración públicoprivada y, lo que resulta más relevante, que estas cantidades no vienen a sufragar un déficit global del contrato en los casos en los que la explotación económica no resulte rentable. Esto impide, además, el que se pueda producir un aumento en los pagos que haya de realizar la Administración al contratista en el supuesto de que se produzca un aumento de los costes de explotación de la infraestructura construida o de sus servicios anejos, ya que, tal como señala Eurostat, esto sería transformar la relación jurídica, que pasaría a estar considerada como un arrendamiento financiero, con distinta valoración contable y, por consiguiente, consolidaría las deudas en el déficit público (Eurostat, 2002, p. 200).

Obviamente, aquí caben que en el contrato se estructuren diversas modalidades de pagos al contratista, fórmulas que han sido valoradas por Eurostat de forma flexible atendiendo a la realidad de cada uno de los contratos que se hayan firmado. De hecho, a título de ejemplo, se puede señalar que la aplicación de esta regla no eliminaría, en principio, la posibilidad de que las cantidades que paga la Administración pública al contratista estén divididas en dos partes, de tal manera que tengan una parte fija y otra que sea directamente dependiente de la calidad del servicio, sin que tenga la consideración de sanción. Obviamente lo que no puede suponer esta dualidad tarifaria es la desnaturalización del contrato, de tal manera que para que esta modalidad resulte admisible es preciso que los pagos han de ser realizados una vez que se haya producido la autorización para el inicio de las actividades, y siempre y cuando el permiso concedido por la Administración pública pueda ser revocada por falta de cumplimiento de la normativa, particularmente cuando se impone la cláusula de progreso o de adaptación tecnológica, con los problemas que ello puede provocar por incremento de los costes al prestador del servicio.

Uno de los elementos en los que más se incide por parte de Eurostat es el relativo al aumento en los costes de puesta a disposición de la Administración del inmueble objeto del contrato. Estas cantidades debe ser, en principio, asumido por el particular, de tal manera que se violaría el principio de la asunción de riesgos por éste si fueran sufragados por la Administración pública, ya que reflejan una mala planificación del coste de puesta en servicio, que ha de ser transferido al contratista y no restar en manos de la Administración. Conviene tener presente que ésta sólo podría hacer frente a un aumento de costes si es la consecuencia de actividades de la Administración en relación con el objeto del contrato, como sería, claramente, en el caso de ejercicio por parte de ésta del ius variandi. En los restantes supuestos el incremento de costes lo ha de asumir en su integridad el contratista, para lograr el efecto de la desconsolidación.

Para una determinación adecuada de las circunstancias en las que aparece la responsabilidad por la disponibilidad, en el contrato han de aparecer concretados los niveles de prestación que tiene que realizar el particular y, al mismo tiempo, que la responsabilidad opere de un modo automático. Desde esta perspectiva, tienen que surtir

un efecto importante sobre sus ingresos/ beneficios. Deben afectar en medida significativa al margen de explotación de la unidad e incluso podrían superarlo en ciertos casos, de tal manera que el socio sufriría una fuerte penalización financiera por su insuficiente o inadecuado rendimiento. Podrán adoptar asimismo la forma de renegociación automática del contrato e, incluso, en un caso extremo, de expulsión del socio original del contrato (Eurostat, 2004, p. 15).

Incluso, como mecanismo de cierre ante posibles comportamientos torticeros por parte de la Administración, se podrían hacer estudios comparativos de los costes que se están facturando para servicios de similar naturaleza, a fin de probar que la exigencia de calidad resulta proporcionada a las características del servicio.

Frente a este automatismo, el análisis de las deducciones por mal funcionamiento de la prestación podría conducirnos a una situación que sí computaría a efectos de déficit: la mala concreción de los niveles de calidad. Esto es, en los supuestos en los cuales esté previsto una alta responsabilidad por parte del contratista pero en donde se haya producido, al mismo tiempo, una concreción laxa de los elementos 
que la hacen surgir, nos encontraríamos con que resulta indicativa de una deficiente traslación de los riesgos al particular, o, planteada la cuestión de forma inversa, nos demostraría que nos encontramos ante la asunción indirecta de los daños producidos por la Administración contratante y no por el contratista.

En este sentido, la cuantía de las sanciones es un elemento relevante a la hora de analizar cómo se ha producido la transferencia de riesgos. El criterio básico que utiliza Eurostat para dilucidar si la sanción es ficticia o por el contrario es real depende del coste de la prestación del servicio: "la reducción en los pagos por la Administración en una cuantía muy inferior a la que correspondería a la parte de servicios no prestados demostraría la existencia de una sanción marginal, lo que sería contrario a la filosofía básica de una transferencia significativa de riesgos al socio" (Eurostat, 2004, pp. 15-16). Obviamente no debe quedar recogido en el contrato un umbral de incumplimiento que resulte sin sanción para el contratista por cumplimiento deficiente del servicio, ya que este elemento operaría como un indicativo de que no se ha producido la necesaria transferencia significativa del riesgo al particular que colabora con la Administración.

Pero, al mismo tiempo, hay que establecer mecanismos adecuados de control por parte de la Administración, que han de estar suficientemente familiarizados con las prestaciones del contrato para que la imposición de este tipo de penalizaciones se pueda establecer de forma real.

Estos incumplimientos del contratista sólo podrían quedar sin sanción por parte del ente público en aquellos supuestos en los que se producen elementos de carácter extraordinarios que son determinantes de la falta de consecución. Así, Eurostat cita específicamente dos que resultan muy expresivos del tipo de circunstancia ante el que nos tenemos que encontrar para que se pueda no materializar la consolidación: "como puede ser un cambio importante de política o un caso de "fuerza mayor". Si bien, tales excepciones sólo se aceptarían en condiciones muy limitadas que deben establecerse expresamente en el contrato" (Eurostat, 2004, p. 15).

\subsection{En particular, la estructuración de los pagos por disponibilidad}

Tal como señalaba el artículo 11.4 LCSP, "la contraprestación a percibir por el contratista colaborador consistirá en un precio que se satisfará durante toda la duración del contrato, y que podrá estar vinculado al cumplimiento de determinados objetivos de rendimiento". En condiciones normales, este pago va a estar vinculado a los referidos objetivos de rendimiento, en la medida en que la estructura de los contratos de colaboración exige una determinación de los niveles de calidad de los servicios prestados por el contratista.

De hecho, en las operaciones de CPP, el modo usual de pago es el denominado pago por disponibilidad, que es el usual en los casos de contratos cuyo objeto es infraestructuras para su utilización para actividades administrativas. Esto es, se trataría de aquellos supuestos en los que se suscriben contratos "para la construcción y financiación de infraestructuras públicas que únicamente va a utilizar la Administración y no terceros usuarios, por lo que en principio no serían explotables económicamente, al menos hacia el mercado. Estaríamos hablando de supuestos en donde no se admite la prestación del servicio por el concesionario sino por la Administración, tales como hospitales, prisiones, colegios, edificios de servicios administrativos (Herranz, 2005, pp. 756-757).

Esto es, nos podemos encontrar tanto ante supuestos en los cuales hay una puesta a disposición de un edificio para la prestación de un servicio en condiciones adecuadas, pero en los que el usuario final va a ser un particular -como ocurre, por ejemplo, con los hospitales- o incluso a los propios servicios administrativos, como ocurre con muchos supuestos de utilización de las fórmulas CPP para las sedes administrativas. En este sentido, lo que se transferiría al particular sería el denominado riesgo por disponibilidad de la infraestructura, que, como sabemos, ha sido definido por Eurostat (2004) como aquél "que hace referencia a aquellos casos en los que, durante la explotación del activo, se reclama la responsabilidad del socio porque a causa de una gestión insuficiente ("mala gestión"), el volumen de los servicios es inferior al contractualmente convenido o su nivel de calidad no satisface la especificada en el contrato".

Ahora bien, no podemos olvidar que en estos supuestos el esquema contractual es especialmente complejo en la medida en que no nos encontramos ante un contrato del que únicamente forme parte la infraestructura, sino que hay una serie de prestaciones complementarias -servicios y calidad de la disponibilidad-, que serían las que determinarían el riesgo económico para el contratista. En este sentido, en estas modalidades de concesión "el concesionario construye, financia y opera la infraestructura, encargándose la Administración competente básicamente de proveer los servicios 
asociados. La adjudicación de la concesión se realiza sobre la base de las propuestas de los licitantes que incluyen un proyecto de diseño realizado teniendo en cuenta especificaciones funcionales definidas por la Administración concedente. La fórmula de financiación utilizada es del tipo presupuestaria diferida, basada en un esquema de pagos por disponibilidad, por el cual se retribuye al concesionario en función de la calidad en la prestación del servicio de operación de la infraestructura según unos parámetros predefinidos en el contrato de concesión" (Herranz, 2005, p. 757).

De este modo, la retribución que abonaría la Administración no sería fija, sino que, por el contrario, dependería de la disponibilidad del inmueble y del cumplimiento de los parámetros de calidad que se hayan pactado entre concedente y concesionario. En este sentido, conviene tener presente que no sólo se producen los pagos por la Administración en función de la utilización, sino que en ocasiones también se utilizan criterios derivados de la evaluación de los estándares de calidad y servicio, que actúan como incentivos para un adecuado nivel de calidad y con penalizaciones para el concesionario en el caso de que la obra no se encuentre en las condiciones requeridas (Acerete, 2004, p. 87). Es lo usual en los casos en los que hay un servicio efectivo -hospitales, colegios, etc.- pero que también se ha utilizado en ocasiones para mejora de autovías ya construidas. Como consecuencia de ello, la remuneración que recibe el concesionario no es fija, sino variable, en función de diversos criterios entre los que está la cantidad y, sobre todo, la calidad del servicio previsto ${ }^{(21)}$. Por lo tanto, se trata de un sistema en el que el pago es efectuado por todos los contribuyentes, quienes asumen el coste final del proyecto, usen o no la infraestructura, si bien los pagos que se deberá realizar por la Administración se realizan de forma escalonada en el tiempo.

Precisamente por ello, el clausulado de los contratos de colaboración entre el sector público y el sector privado ha de estar muy vinculado a la realidad de los denominados pagos por disponibilidad, debiendo recoger, asimismo, un desplazamiento suficiente del riesgo de la Administración al contratista; lo que se puede estructurar de la siguiente manera:

a) De entrada, se puede recoger una cantidad fija que pague la Administración al concesionario, pero bajo ciertas condiciones. Se trata de cantidades que no se pueden empezar a pagar por parte del ente que ha otorgado la concesión con anterioridad a la entrega del inmueble a la Administración. De igual modo, estas cantidades fijas no pueden tener una magnitud que cubran todos los costes de construcción de la infraestructura. Si ocurriera de este modo, realmente no nos encontraríamos ante una concesión de obra pública por faltar el elemento del riesgo que ha de asumir el contratista de la Administración pública ya que es ésta la que cubre el riesgo total de la operación.

b) La segunda parte de lo que abonaría la Administración, la relativa a los ingresos variables dependientes de la calidad del servicio no deben ser la consecuencia sólo de sanciones por el mal funcionamiento del servicio sino que deben estar estructurados sobre la cantidad y calidad del mismo, de tal manera que el riesgo económico de la concesión se materializaría si el servicio no alcanza toda la calidad requerida por la Administración, con lo que el riesgo económico aparecería aún si no hay, en sentido técnico, incumplimiento sino mero cumplimiento discreto, en la zona de los mínimos admisibles ${ }^{(22)}$. En esta línea, ha de procederse a un examen continuo del funcionamiento del servicio para adecuar las cantidades que ha de abonar la Administración al concesionario.

En este sentido, debería existir una diferenciación clara entre lo que son sanciones por el mal funcionamiento del servicio y la determinación de las partidas por las que puede cobrar el concesionario, atendiendo a niveles de calidad, que obviamente deberían ser variables en función de las circunstancias y de los avances técnicos y sociales, por lo cual habrán de ser fijadas con la mayor

(21) Véase sobre esta modalidad de retribución los trabajos de Agueda, F., a financiación... op., cit. el estudio de Ruiz, A. (2000). Aplicaciones recientes en materia de financiación privada de infraestructuras en España: entre la financiación presupuestaria diferida y las fórmulas concesionales. En La participación del sector privado en la financiación de infraestructuras y equipamientos públicos: Francia, Reino Unido y España (Elementos comparativos para un debate). Instituto de Estudios Económicos y la Editorial Civitas.

(22) Eurostat es clara sobre este punto cuando señala que "se supone que la Administración no lo soporta si está legitimada para reducir en medida importante sus pagos periódicos, como cualquier "cliente normal", caso de no satisfacerse ciertos criterios de rendimiento. Bajo estas condiciones, los pagos por la Administración dependerán del nivel efectivo de disponibilidad asegurado por el cliente privado durante un período de tiempo determinado". 
nitidez posible. En todo caso, si hubiera penalidades, un mal funcionamiento del servicio debería suponer una reducción significativa de los pagos que realice la Administración concedente.

Se ha de proceder a la determinación de una cuantía máxima anual que percibiría el concesionario de la Administración sólo en el caso de la mejor prestación del servicio tal como está recogida en la concesión. En este sentido, las rebajas en la retribución por servicios prestados con una calidad inferior deberían poder condicionar la rentabilidad económica de la explotación de la concesión. Precisamente porque la retribución depende de la calidad, deberían estar previstos expresamente controles por parte de la Administración ${ }^{(23)}$. Si no estuvieran previstos o si no se hicieran sería un indicio de que el contrato de concesión de obra pública encubre, en su realidad económica, uno de obra cuyas cláusulas económicas sí se consolidarían en la contabilidad de la Administración contratante.

\section{Riesgos de demanda}

La última modalidad de riesgo que ha de ser transferida por las Administraciones públicas al contratista y que ha de ser analizada, conforme a la doctrina de Eurostat sobre la consolidación de infraestructuras, está constituida por los denominados riesgos de demanda. De acuerdo con lo que se ha señalado por la Oficina estadística europea, los riesgos de demanda serían:

aquellos que cubren aquellas variaciones en la demanda (superior o inferior a la prevista en el momento de firmarse el contrato) que no dependen de la actuación del socio privado. En otras palabras, un desplazamiento de la demanda no puede estar vinculado a una calidad insuficiente de los servicios prestados por el socio, sino que resulta de otros factores como pueden ser el ciclo económico, nuevas tendencias del mercado, cambio en las preferencias de los usuarios finales u obsolescencia tecnológica. Forma parte del riesgo económico que habitualmente soportan las entidades privadas en una economía de mercado (Eurostat, 2004, p. 9).

De forma sintética, se puede señalar que la Administración contratante retiene el riesgo de demanda de una operación de construcción de infraestructuras cuando está obligada al pago de una determinada cantidad al particular con independencia de cuál sea la utilización efectiva del bien, con lo que la rentabilidad económica para el contratista está garantizada contractualmente, al resultar totalmente independiente de la demanda real del servicio. De este modo, estaría vetada por efecto del principio de estabilidad presupuestaria la denominada garantía de beneficio empresarial a que algunos hacen referencia, incluso esta recogido en alguna norma española, y que se analizará con la concesión de obra pública.

En definitiva, lo que se pretende es que ante respuestas negativas de los consumidores con respecto a un determinado bien, el contratista debe adoptar soluciones empresariales para aumentar la aceptación del mismo sin recurrir a garantías de la Administración, que demostrarían que es el que ha retenido los riesgos que se pueden producir con la operación. En este sentido, la realización de todo tipo de actividades para impulsar el uso del bien, que van desde el elemento que resulta más común, la publicidad de la infraestructura, hasta otros más complejos como la diversificación del uso del bien -que, obviamente, ha de estar aceptada de forma previa en el contrato o, en su defecto, ser pactada con la Administraciónson indicativos de que el riesgo de la demanda es soportado por el particular y, por consiguiente, la inversión para la construcción de la infraestructura no se consolidará en las cuentas de la Administración pública.

Como es fácil de entender, este planteamiento de Eurostat hace que haya que ser especialmente cuidadoso en la formulación de algunas modalidades de concesión de obra pública en las que es la Administración concedente la que efectúa los pagos al contratista, como son las de peaje en la sombra o la de peajes mixtos $o$, incluso, en algunas modalidades de peaje en la sombra en donde no hay una cantidad fija, como se estructura el peaje por bandas. Y sin duda condiciona mucho la aplicabilidad de los mínimos de peaje que han de abonar las Administraciones, el sistema que ha sido típico en Chile, sobre todo si las cantidades cubren la amortización de la construcción de la infraestructura. Y, precisamente por esto también resultan problemáticas, desde el punto de vista de la estabilidad presupuestaria, las aportaciones

(23) Eurostat lo recoge expresamente cuando indica que "Lo anterior sería de aplicación especialmente en el caso de que el socio no satisfaga los niveles de calidad requeridos debido a una falta de cumplimiento, con la resultante indisponibilidad del servicio, bajo nivel de la demanda efectiva por parte de usuarios finales o bajo nivel en la satisfacción del usuario. Dichos extremos vienen generalmente reflejados en indicadores de cumplimiento en el contrato". 
a la explotación de la obra que están recogidas en la normativa de la concesión de obra pública.

Incluso, de acuerdo con lo señalado por Eurostat, si se produjera una decisión administrativa que afectara directamente al volumen de la demanda de utilización del bien -el caso típico estaría constituido por la construcción de una infraestructura que haga competencia a la ya construida- y esto supone incluso que se ha de producir por parte del ente público un pago compensatorio al contratista, aquí no nos encontramos ante la consolidación contable en la Administración sino que se trataría de abonos de cantidad admitidos, precisamente por la imprevisibilidad del riesgo en el momento de producirse la primera construcción ${ }^{(24)}$.

Por último, de acuerdo con el esquema del SEC 95 también se podrían producir pagos al contratista en casos de acontecimientos externos de naturaleza excepcional, en casos de fuerza mayor, sin que se produzca la consolidación en las cuentas de la Administración pública de la que depende la obra construida. Estos supuestos se admitirán sólo en condiciones muy restrictivas, en las que no hay coberturas de seguro a precio razonable, ya que en supuestos normales el contratista está obligado a suscribir una póliza de seguros para recuperarse de los daños padecidos en el bien. Lo que desde luego no es admisible es que sea la Administración pública la que actúe como seguro a todo riesgo de los daños que acontezcan al contratista.

\section{La transferencia de riesgos en el SEC 2010 como criterio para la transferencia del riesgo operacional}

Las consideraciones anteriores no se deben entender como un ejercicio contable en el marco de un análisis jurídico. Más allá de la permeabilidad de los parámetros de estudio de los contratos, aquí encontramos un vehículo muy adecuado para ver en qué circunstancias nos estamos encontrando ante una figura de CPP y cuándo ante otras modalidades contractuales y cómo valoramos la transferencia de riesgos. Porque precisamente, lo que hace Eurostat, y con él los institutos estadísticos de los estados miembros, es examinar los flujos económicos y dónde se queda el Estado actuando como salvaguarda del contratista. Algo que es exactamente igual de útil en la colaboración público-privada que en las concesiones.

Esta división de las modalidades de riesgo sirve, de este modo, para analizar cuándo se ha transferido el riesgo operacional, en las condiciones previstas en el Considerando
18 de la Directiva 2014/23, de concesiones, cuando afirma que "la característica principal de una concesión, el derecho a explotar las obras o los servicios, implica siempre la transferencia al concesionario de un riesgo operacional de carácter económico".

\section{Referencias bibliográficas}

Acerete, J. (2004). Financiación y gestión privada de infraestructuras y servicios públicos. Asociaciones público-privadas [tesis doctoral, Universidad de Zaragoza]. Instituto de Estudios Fiscales. http://imagenesbibliotecacentral. minhap.gob.es/pdfpublicaciones/Literaturagris/ financiaciongestionprivadainfraestructuras serviciospublicos.pdf

Comisión Europea. (2004). Sobre la colaboración público-privado y el Derecho comunitario en materia de contratación pública y concesiones. Comisión de las Comunidades Europeas. https://eur-lex.europa.eu/legal-content/ES/TXT/ PDF/?uri=CELEX:52004DC0327

Dipace, R. (2006). Partenariato pubblico privato e contratti atipici. Milano - Dott. A. Giuffrè Editore.

Eurostat. (2002). Manual del SEC 95 sobre el déficit público y la deuda pública. Oficina de Publicaciones Oficiales de las Comunidades Europeas.

Eurostat. (2004, 11 de febrero). Decisión 18/2004, relativa a la no inclusión del fentión en el anexo I de la Directiva 91/414/CEE del Consejo y a la retirada de las autorizaciones de los productos fitosanitarios que contengan esta sustancia activa. Boletín Oficial del Estado. https://www.boe.es/buscar/doc. php?id=DOUE-L-2004-80296

Eurostat. (2004). Long Term Contracts Between Government Units And Non-Government Partners (Public-private-partnerships). Oficina de Publicaciones Oficiales de las Comunidades Europeas.

Gómez-Ferrer, R. (2003). Comentarios a la Ley de contratos de las Administraciones Públicas (2. ed.). Editorial Civitas.

González, J. (2006). El contrato de colaboración público privada. Revista de Administración Pública, 170, 7-39.

Herranz, P. (2005). Régimen general de las obras

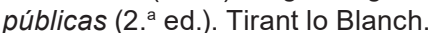

(24) Eurostat. (2004, 11 de febrero). Decisión 18/2004, relativa a la no inclusión del fentión en el anexo / de la Directiva 91/414/CEE del Consejo y a la retirada de las autorizaciones de los productos fitosanitarios que contengan esta sustancia activa. Boletín Oficial del Estado. 
López-Muñiz, J. (1997). ¿Sociedades públicas para construir y contratar obras públicas? Revista de Administración Pública, 144, 45-73.

Míguez, L. (2008). Las formas de colaboración público-privada en el Derecho español. Revista de Administración Pública, 175, 157-215.

Pina, V. \& Torres, L. (2004). La iniciativa privada en el sector público: externalización de servicios y financiación de infraestructuras. Asociación
Española de Contabilidad y Administración.

Ruiz, A. (2002). Reivindicación de una cultura de gestión concesional. Apuntes críticos sobre el proyecto de ley básica reguladora de la concesión de obras públicas. Revista de Obras Públicas, 3425, 173 180.

Villar, F. (2007). "La concesión como modalidad de colaboración privada en los servicios sanitarios y privados". Revista de Administración Pública, 172, 141-168. 